\title{
Mobile health
}

\author{
A medicina de bolso
}

Alexandra Monteiro ${ }^{1}$

mHealth, or mobile health is a term associated with the daily practice of medicine and public health supported by mobile devices such as cell phones and tablets. It is an universal trend of convergence of all patients' information and images, data banks as source of information, academic social networks, specialized remote support systems and alike, as a support to the medical practice and to the teaching of medicine. Additionally there is the possibility of access by patients to their reports, tests results and schedules. However, other low-cost technologies are available, such as Raspberry $\mathrm{Pi}$, a credit-card-sized computer developed in the United Kingdom by the Raspberry Pi Foundation $^{(1)}$. Such project was aimed at facilitating and encouraging the teaching of computer sciences for children in that country, and involving the study of computer techniques, methods and tools, processes automation and development of solutions based on the use of digital processing. The suc-

1. PhD, Associate Professor, School of Medical Sciences, Universidade do Estado do Rio de Janeiro (UERJ), Rio de Janeiro, RJ, Brazil. E-mail: monteiroamv@gmail.com. cess of this project has motivated the development of other applications, in health inclusive, also proposing its utilization as a medical DICOM images viewer. The hardware as a whole is integrated into a single board which may be coupled to a display monitor, but obviously without meeting the minimum requirements for communication protocols, file or algorithm format in agreement with the current DICOM and HL standards ${ }^{(2)}$. Probably, such a solution may be useful for clinicians to visualize images, but, strictly speaking, should not be utilized as a working tool for the radiologist. The present issue of Radiologia Brasileira introduces the theme "Raspberry Pi: a 35-dollar device for viewing DICOM images"(3). Therefore, this is a worthwhile opportunity to reflect on the theme.

\section{REFERENCES}

1. Fundação Raspberry Pi. [acessado em 17 de março de 2014]. Disponível em: http://www.raspberrypi.org/.

2. Manual de certificação para sistemas de registro eletrônico em saúde. [acessado em 17 de março de 2014]. Disponível em: http://www.sbis.org.br/indexframe.html.

3. Paiva AO, Moreira RO. Raspberry Pi: dispositivo de 35 dólares para visualização de imagens DICOM. Radiol Bras. 2014;47:99-100. 